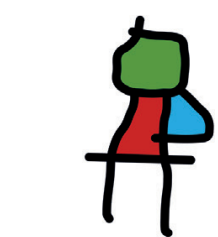

SEICAIP

\section{Allergologia et \\ immunopathologia}

Sociedad Española de Inmunología Clínica,

Alergología y Asma Pediátrica

www.all-imm.com



ORIGINAL ARTICLE

OPEN ACCESS ㄷㅇ(1)(2)

\title{
Prevalence of recurrent wheezing in infants and toddlers in Barbados: findings from a prospective study of a cohort of babies born during 2015-2017
}

\author{
Alok Kumar ${ }^{\mathrm{a}, \mathrm{b} *}$, Prerna Singh ${ }^{\mathrm{a}}$, Nico Belgrave \\ ${ }^{a}$ Faculty of Medical Sciences, The University of the West Indies (Cave Hill), Barbados \\ ${ }^{b} T h e$ Queen Elizabeth Hospital, Bridgetown St. Michael, Barbados
}

Received 17 April 2020; Accepted 30 October 2020

Available online 2 January 2021

\section{KEYWORDS \\ infants; \\ toddlers; \\ prevalence; \\ asthma predictive \\ index; \\ recurrent wheezing}

\begin{abstract}
Objectives: The main objective was to determine the prevalence of recurrent wheezing (RW) among infants and toddlers as well as the prevalence of asthma predictive risk factors among those with RW.

Materials and methods: A prospective study of a cohort of babies recruited after their birth during July 2015-June 2017. Mothers were contacted using the WhatsApp messaging system for digital follow-up on their baby's condition at 3-monthly intervals until they were 18 months old. Information on wheezing and its correlates were collected by digital follow-up and corroborated at an in-person interview and examination of their baby at 18 months of age. Recurrent wheezing was defined as more than three episodes of wheezing or its correlates during the follow-up period.

Results: There were 338 males (41.5\%) and 476 (58.5\%) females. Overall, $31.1 \%(95 \% \mathrm{Cl}=27.9 \%$, $34.4 \%$ ) had RW by 18 months and the same number had RW during their first year of life. Of the infants with RW, $121(47.8 \%$; $95 \% \mathrm{Cl}=41.6,54.2)$ had at least one or both of the major criteria and/or at least two minor criteria of the stringent Asthma Predictive Index (API). Of those with RW, $32.0 \%$ received antihistamine and $20 \%$ had received antibiotics on their last visit to a physician for wheezing or symptoms of cough, cold, and/or breathing difficulty.

Conclusions: Nearly a third of infants and toddlers had RW and nearly half of the infants with RW had risk factors fulfilling the criteria of the stringent API.

(c) 2021 Codon Publications. Published by Codon Publications.
\end{abstract}

*Corresponding author: Professor Alok Kumar. Faculty of Medical Sciences at The Queen Elizabeth Hospital, Martindales Road, Bridgetown St. Michael, Barbados. Email address: alok.kumar@cavehill.uwi.edu; alokkumar.uwichill@gmail.com 


\section{Introduction}

Asthma is a chronic inflammatory disease of the airway that causes a reversible airflow obstruction characterized by symptoms such as wheezing, chest tightness, and/or coughing. Making a diagnosis of asthma in early childhood is difficult. This is largely in part due to the heterogeneity of asthma, which has been recognized., ${ }^{1,2}$ The classical approach to making the diagnosis of asthma has been to define asthma based on clinical diagnostic criteria and then using atopic or allergic features to identify subgroups of asthma or what is now considered to be phenotypes of asthma. ${ }^{1-4}$ Symptoms of airway obstruction such as recurrent wheezing (RW) and features suggestive of reversible airway obstruction are central to most asthma definitions and support the diagnosis of asthma. However, wheezing in early childhood has different causes. On many occasions, acute respiratory infections (ARI) can be associated with wheezing and vice versa acute exacerbation of asthma can be triggered by an ARI in young children. Then, there is the possibility of viral infection causing damage to the airway and predisposing to asthma. Thus, a complex relationship between wheeze, ARI, and asthma exists in early childhood. There are different phenotypes of asthma in children who present with RW. ${ }^{5-7}$ One of the many reported classifications of asthma phenotypes categorizes children with RW into those who are (1) transient wheezers; (2) non-atopic wheezers; and (3) persistent wheezers. ${ }^{6} \mathrm{RW}$ in young children has been shown to be an important objective correlate of asthma phenotypes in several studies. ${ }^{8-10}$

It is commonly agreed that recurrent symptoms of airway obstruction such as wheezing, cough, and chest tightness are non-specific manifestations of more than one phenotype of asthma and a significant proportion of these children would not wheeze as older children and adults. ${ }^{6,7}$ It is, therefore, difficult to predict which of these children will go on to wheeze or have asthma as older children and adults. ${ }^{11}$ The Asthma Predictive Index (API) originally proposed by Castro-Rodriguez provided a framework to predict outcomes of early childhood RW. ${ }^{10}$ Despite their intrinsic and practical limitations, results from recent studies have confirmed the usefulness of early clinical predictor indices of asthma such as the stringent API for identifying young children at risk for later development of asthma. ${ }^{12-14}$ This prediction about the risk of asthma in later childhood and adulthood assumes added significance for adequate treatment of these children presenting with symptoms of RW in early childhood. It has been shown that both under-treatment and over-treatment is common in young children presenting with RW..$^{15}$

Barbados, one of the English Caribbean countries has a population of 284,000 which includes 53,000 children under the age of 16 years. It is reported to have a fairly high prevalence of Asthma among school children. ${ }^{16}$ Asthma is a common cause of hospital admissions in this country. ${ }^{17}$ However, there are no regional prospective studies on the epidemiologic characteristics of RW in the first few years of life. In this study, we determine the prevalence of RW which is central to most asthma phenotypes among a cohort of toddlers recruited at birth and followed up to 18 months. Additionally, we report on the prevalence of asthma predictive risk factors in the same cohort. We also explore the management of young children with RW.

\section{Materials and methods}

\section{Study design, cohort enrollment, and ethical approval}

This is a prospective study of a cohort of children recruited immediately after their birth. Over $90 \%$ of all deliveries in Barbados take place at the Queen Elizabeth Hospital (QEH), which is the only publicly funded tertiary care hospital in this country. All newborns after their delivery are cared for by the admitting pediatric consultant until the time of discharge. Recruitment was done during the period between July 2015 and June 2017. Babies born on the days when the principal investigator (PI) was the consultant pediatrician responsible for admissions at the QEH (on an average of six admission days per month) were eligible for enrollment in this study. Babies that were sick and required care in the neonatal intensive care unit and those that were premature or had any other abnormality such as major congenital malformations were excluded from enrollment. Babies were also excluded from enrollment if their mother did not use the WhatsApp messaging system, as it was the proposed tool to be used for digital follow-up of the babies in this study. Informed consent was sought from the mother of the babies eligible for enrollment. Babies of consenting mothers were enrolled in this study.

Necessary ethical approval was obtained from the ethics committee at the QEH. Informed written consent was obtained from the mothers of all newborn babies enrolled in this study cohort.

\section{Baseline data collection}

All mothers of the babies enrolled in this study had a 10-minute interview with the PI prior to their discharge from the hospital. This interview was used to record historical baseline data on asthma and allergies in the parents and any siblings, to counsel the mother on symptoms of asthma, atopic dermatitis (AD), and allergic rhino-conjunctivitis (ARC) in babies, to discuss the follow-up processes and to record the mother's WhatsApp phone number. They were advised to seek appropriate medical attention for any symptoms of asthma, AD or ARC at the appropriate medical facility as they would have done otherwise. Additionally, the mother was advised to maintain a record of the symptoms of asthma, AD, ARC with the date of onset and of the visit to a physician for these symptoms along with the date, the diagnosis and the treatment given to the child, if any. An enrollment number was assigned to the baby (to be used for identification purposes during the follow-up) as well as the name and contact WhatsApp number of the PI was shared with the mother via a WhatsApp message for her record. Additionally, she was given the option of using WhatsApp for raising any queries with the PI about any medical problem in her baby.

\section{Study cohort follow-up}

In keeping with the pre-decided study protocol, mothers of all the babies in this cohort were contacted using 
the WhatsApp messaging system at 3, 6, 9, 12, 15, and 18 months of age for follow-up. This follow-up was conducted by the PI to ensure privacy and personal data protection. Mothers were asked several questions from a predesigned questionnaire. The PI also answered any specific question pertaining to her child's wheezing or other related allergic conditions.

Additionally, mothers of babies who had RW during the 18-month follow-up period were called in for an in-person interview at a mutually agreed convenient time soon after the baby was 18 months old. The interview was designed for $30 \mathrm{~min}$ and both the mother and the baby were seen for this interview. The same questionnaire used for the digital follow-up was again used for the in-person interview. During this in-person interview, data collected from the mother during the digital follow-up at $3,6,9,12,15$, and 18 months were corroborated with the mother and the record maintained by the mother. Additionally, all the records of doctors' visits and medications prescribed for the child in the past 18 months that were available from the mother were reviewed. The child was also examined for any tell-tale signs of $A D$ or $A R C$ that were present.

\section{Data collection questionnaire}

The set of questionnaires used for the digital follow-up as well as for the maternal in-person interview after the 18th month was compiled based on the International Study of Asthma and Allergies in Childhood (ISAAC) core questionnaires and questionnaire developed by the International Study of Wheezing in infants with adaptations to suit the local practices in this country. ${ }^{18,19}$ Items in the questionnaire were designed to collect information on physician-diagnosed asthma, wheezing, and other correlates of wheezing such as nocturnal cough, use of asthma medications such as inhalers (Ventolin or Berotec or Asthalin), or oral medications such as Bronchomat or Ventolin (Salbutamol containing oral syrup that is locally available) or nebulization for illness with cold, cough, and breathing difficulty. The second set of questions were designed to elicit historical features suggestive of $A D$ in the child, historical features suggestive of ARC such as recurrent sneezing bouts, recurrent cold without fever, itching or rubbing of nose, runny or recurrent episodes of red discoloration or itching or eyes. The third set of questions were designed to elicit factors predictive of asthma in children with RW. Additionally, there were questions (fourth set) to collect information on all consultations with a physician for symptoms of wheezing, cough, cold, breathing difficulty or any of the symptoms of $A D$ and $A R C$ including diagnosis and treatment. Lastly, there were questions (fifth set) on the use of any home remedies, over-the-counter medications and/or medications prescribed by a physician which the mother had used for wheezing in her child.

\section{Measured outcome}

The outcome measured included prevalence of RW which was defined as a history of wheezing and/or other possible correlates of wheezing such as the use of prescribed oral bronchodilator medications, use of prescribed asthma inhalers, and having been nebulized for cough and cold at a health care facility on more than three occasions. The prevalence of RW was assessed at 12 months and then again at 18 months. Additional outcome measures included prevalence of the major and minor criteria of the stringent API. ${ }^{20}$ The third set of outcomes measured included the point of care and the nature of treatment received during the last episode of wheezing.

\section{Data management and statistical analysis}

Data collection, both at the time of digital follow-up and during the face-to-face interview was accomplished using a data collection sheet. The data collection sheets were anonymized by the use of enrollment numbers assigned at the time of enrollment. At the start of digital follow-up as well as during the face-to-face interview, the mother was asked to confirm the enrollment number of her child. All data were entered into a Microsoft Access database on the day of data collection by a research assistant who was given one day's training in the data entry technique. The database itself was also anonymized with enrollment number as the only identifier and was password protected. All data pertaining to the enrollment itself was stored in a password-secured Microsoft Access database where the child was identified by the mother's initials followed by the date of birth and the mother was identified by the mother's initials followed by her mobile phone number. This database was used by the principal investigator for contacting the mother for the follow-up of her child. Microsoft Excel was used for basic data analysis and generation of tables and graphs. Statistical analyses were performed using Vassar Statistical package. Categorical variables were reported as frequency counts and percentages with a 95\% Confidence Interval (continuity correction). They were compared using the Chi-square test. The strength of the association was analyzed using Odds Ratio. $P$ values of less than 0.05 were accepted as statistically significant.

\section{Results}

\section{Cohort characteristics}

There were 944 newborns, consisting of 457 (48.4\%) males and 487 (51.6\%) females, born during July 2015 through June 2017, who were enrolled in this study cohort. Over the same period, there were a total of 5198 live births at the QEH which consisted of 2507 (48.2\%) males and 2691 (51.8\%) females. Among the babies enrolled in the study cohort, 130 (13.8\%) were lost to follow-up. Table 1 shows the characteristics of the babies enrolled in this study. Of the 814 toddlers who completed at least 18 months follow-up and had a clinical assessment along with a faceto-face interview of their mother, there were 338 males (41.5\%) and 476 (58.5\%) females. This difference in gender proportion of the final study cohort when compared to the cohort at enrollment was statistically not significant $(P=0.0612)$. 
Table 1 Characteristics of the 944 babies enrolled in the study cohort.

\begin{tabular}{|c|c|c|}
\hline Characteristics & $\begin{array}{l}\text { Study cohort } \\
\qquad \begin{array}{c}(\mathrm{N}=944) \\
\text { No. }(\%)\end{array}\end{array}$ & $\begin{array}{c}\text { All livebirths } \\
(\mathrm{N}=5198) \\
\text { No. (\%) }\end{array}$ \\
\hline \multicolumn{3}{|l|}{ Birth weight for gestational age } \\
\hline Small for gestational age & $61(6.5)$ & 597 (11.5) \\
\hline $\begin{array}{l}\text { Appropriate for gestational } \\
\text { age }\end{array}$ & $847(89.7)$ & $4373(84.1)$ \\
\hline Large for gestational age & $36(3.8)$ & $228(4.4)$ \\
\hline \multicolumn{3}{|l|}{ Gender } \\
\hline Male & $457(48.4)$ & 2507 (48.2) \\
\hline Females & $487(51.6)$ & $2691(51.8)$ \\
\hline \multicolumn{3}{|l|}{ Parity } \\
\hline Primi-parous & $328(34.7)$ & $1966(37.8)$ \\
\hline Multi-parous & $616(65.3)$ & $3232(62.2)$ \\
\hline \multicolumn{3}{|l|}{ Maternal age } \\
\hline$\leq 20$ Years & $274(29.0)$ & $1567(30.3)$ \\
\hline 21-35 Years & $580(61.4)$ & 3052 (58.7) \\
\hline$\geq 35$ Years & $90(9.5)$ & 579 (11.1) \\
\hline \multicolumn{3}{|l|}{ Antenatal care } \\
\hline Yes & $908(96.2)$ & $4781(95.8)$ \\
\hline No & $36(3.8)$ & 417 (4.2) \\
\hline
\end{tabular}

\section{Prevalence of $R W$ in toddlers}

The prevalence rate of RW in this cohort of toddlers who were followed up from birth until 18 months is shown in Table 2. Overall, there were $253(31.1 \% ; 95 \% \mathrm{Cl}=27.9,34.4)$ toddlers who had RW during their 18-month follow-up. The same number, 253 (31.1\%; 95\% Cl = 27.9, 34.4), of children had RW during the first year of life. No new cases of RW were added at the 15- or 18-month follow-up. There were $91 / 165$ (55.1\%; $95 \% \mathrm{Cl}=47.2 \%, 62.8 \%)$ occasions where a mother reported to have used oral asthma medication that was prescribed by a physician for cough, cold, and/or breathing difficulty in her toddler but not being aware that the medication was prescribed for wheezing. Similarly, there were $48 / 143$ (33.6\%; $95 \% \mathrm{Cl}=26.0 \%, 42.0 \%$ ) occasions where a mother reported that the toddler was nebulized on a visit to the physician for cough, cold, and/or breathing difficulty but did not know that it was for wheezing in her child.

\section{Prevalence of factors associated with the high prediction of asthma}

The prevalence rates of the asthma predictive factors among infants with RW and among those without RW during the first year of life are shown in Table 3. History of physician-diagnosed $A D(O R=1.52 ; 95 \% \mathrm{Cl}=1.11,2.07$; $P=0.0106), A R C(O R=2.37 ; 95 \% C l=1.72,3.76 ; P<0.0001)$, and physician-diagnosed asthma in parents $(O R=1.64 ; 95 \%$ $\mathrm{Cl}=1.16,2.31 ; \mathrm{P}=0.0050$ ) were all significantly more common among toddlers with RW. Of the toddlers with RW, 121 (47.8\%; $95 \% \mathrm{Cl}=41.6,54.2)$ had at least one or both of the major criteria and/or two or more minor criteria
Table 2 Prevalence of recurrent wheezing and/or correlates of wheezing at 18 months of age among a cohort of toddlers born during 2015 through 2017 in Barbados.

\begin{tabular}{|c|c|c|}
\hline $\begin{array}{l}\text { Follow up data on recurrent } \\
\text { wheezing and/or correlates of } \\
\text { wheezing }\end{array}$ & $\begin{array}{c}\text { Number } \\
(n=814)\end{array}$ & $\begin{array}{c}\% \\
(95 \% \mathrm{Cl})\end{array}$ \\
\hline Asthma diagnosed by a physician & 11 & $\begin{array}{c}1.4 \\
(0.7,2.5)\end{array}$ \\
\hline $\begin{array}{l}\text { Wheezing detected by a physician } \\
\text { or a nurse }\end{array}$ & 176 & $\begin{array}{c}21.6 \\
(18.9,24.6)\end{array}$ \\
\hline $\begin{array}{l}\text { Use of asthma inhalers prescribed } \\
\text { for cough, cold or breathing } \\
\text { difficulty }\end{array}$ & 89 & $\begin{array}{c}10.9 \\
(8.9,13.3)\end{array}$ \\
\hline $\begin{array}{l}\text { Use of oral asthma medications } \\
\text { prescribed for cough, cold, } \\
\text { breathing difficulty }\end{array}$ & 165 & $\begin{array}{c}20.3 \\
(17.6,23.2)\end{array}$ \\
\hline $\begin{array}{l}\text { History of nebulization treatment } \\
\text { for cough, cold or breathing } \\
\text { difficulty }\end{array}$ & 143 & $\begin{array}{c}17.6 \\
(15.1,20.4)\end{array}$ \\
\hline $\begin{array}{l}\text { Physician-diagnosed Asthma; } \\
\text { OR wheezing and/or use of } \\
\text { prescribed asthma inhalers/oral } \\
\text { medicine/history of nebulization } \\
\text { on more than three occasions. }\end{array}$ & 253 & $\begin{array}{c}31.1 \\
(27.9,34.4)\end{array}$ \\
\hline
\end{tabular}

of the stringent API. Of note, $52.2 \%$ of toddlers with RW did not have the required number of criteria predictive of asthma in later childhood. There were 45/144 (31.2\%; $95 \% \mathrm{Cl}=23.9 \%, 39.6 \%$ ) occasions among toddlers with RW and $130 / 561$ (23.2\%; $95 \% \mathrm{Cl}=19.8 \%, 26.9 \%)$ among toddlers without RW where there was a history suggestive of (including a prescription of steroid cream from a physician) $A D$ but the mother was informed of a diagnosis of $A D$. The difference in the rate diagnosis from a physician and those based on historical features suggestive of $A D$ was statistically significant $(P<0.0001)$. Similar differences in the rates were seen between the physician-diagnosed ARC and the historical features suggestive of ARC $(P<0.0001)$ as well as between the rates of physician-diagnosed parental asthma and history suggestive of parental asthma $(P<0.0001)$.

\section{Point of care and discharge medication for acute onset wheezing or its correlates}

Table 4 shows the point of care during the last visit to a physician for wheezing or where medications for wheezing were prescribed by a physician among the cohort of 253 toddlers with RW. Overall, 121 (47.8\%; 95\% Cl = 41.6\%, $54.2 \%)$ toddlers with RW during their last acute presentation with wheezing or symptoms of cold, cough, or breathing difficulty for which medications to relieve wheezing were prescribed, received their medical care at the government-funded primary health care centers (polyclinics). For the toddlers with RW, a recall or record of discharge medications prescribed during the last visit to a physician for wheezing or symptoms of cold, cough, and/or breathing difficulty where one or more medications to relieve wheezing was prescribed is shown in Table 5. 
Table 3 Prevalence rates of asthma predictive factors a mong a cohort of infants born during 2015 through 2017 in Barbados.

\begin{tabular}{|c|c|c|}
\hline Asthma Predictive Factors & $\begin{array}{l}\text { Recurrent Wheezing } \\
\qquad(\mathrm{n}=253) \\
\text { Numbers }(\% ; 95 \% \mathrm{Cl})\end{array}$ & $\begin{array}{l}\text { Without Recurrent Wheezing } \\
\qquad(\mathrm{N}=561) \\
\text { Numbers }(\% ; 95 \% \mathrm{Cl})\end{array}$ \\
\hline History of physician-diagnosed Atopic Dermatitis & $99(39.1 ; 33.1,45.5)$ & $167(29.8 ; 26.1,33.8)$ \\
\hline History suggestive of Atopic Dermatitis & $144(56.9 ; 50.6,63.1)$ & $297(52.9 ; 48.7,57.1)$ \\
\hline $\begin{array}{l}\text { History of physician-diagnosed Allergic } \\
\text { Rhino-Conjunctivitis }\end{array}$ & $103(40.7 ; 34.6,47.1)$ & $126(22.5 ; 19.1,26.2)$ \\
\hline History suggestive of Allergic Rhino-Conjunctivitis & $154(60.9 ; 54.5,66.9)$ & 209 (37.3; 33.3, 41.4) \\
\hline $\begin{array}{l}\text { History of physician-diagnosed asthma in one or } \\
\text { both parents }\end{array}$ & $71(28.1 ; 22.7,34.1)$ & 108 (19.2; 16.1, 22.8) \\
\hline History suggestive of asthma in one or both parents & $89(35.2 ; 29.4,41.5)$ & $135(24.1 .4 ; 20.6,27.9)$ \\
\hline
\end{tabular}

Table 4 Point of care during the last visit to a physician 476 for wheezing or cold, cough or breathing difficulty where medications to relieve wheezing was prescribed among cohort of 253 toddlers with recurrent wheezing in Barbados.

\begin{tabular}{lcc}
\hline & $\begin{array}{c}\text { Point of care } \\
(\mathrm{n}=253)\end{array}$ & $\begin{array}{c}\text { Number } \\
(\% ; 95 \% \mathrm{Cl})\end{array}$ \\
\hline Publicly funded Polyclinic & 121 & $(47.8 ; 41.6,54.2)$ \\
$\begin{array}{l}\text { Private paediatrician } \\
\text { Private General } \\
\quad \text { Practitioners }\end{array}$ & 49 & $(19.4 ; 14.8,24.9)$ \\
$\begin{array}{l}\text { Accident and Emergency } \\
\quad \text { at QEH }\end{array}$ & 36 & $(14.2 ; 10.3,19.3)$ \\
$\begin{array}{l}\text { Alternative Practitioners } \\
\text { P }\end{array}$ & 29 & $(11.5 ; 7.9,16.2)$ \\
\end{tabular}

Overall, $173(68.4 \% ; 95 \% \mathrm{Cl}=62.2,74.0)$ toddlers with RW who visited a physician for an acute onset wheezing and/or cold, cough, or breathing difficulty were discharged home on oral bronchodilator medication compared with 88 (34.8\%; $95 \% \mathrm{Cl}=29.0,41.0)$ discharged on inhaled short-acting bronchodilators. This difference in the proportion of toddlers discharged on oral and inhaled bronchodilators was statistically significant $(P<0.0001)$. All 67 toddlers discharged on inhaled corticosteroids had received inhaled short-acting bronchodilators on discharge. There were 10 (4.0\%; $95 \% \mathrm{Cl}=2.0 \%, 7.4 \%)$ toddlers who were not discharged on any medication for the relief of their wheezing although they received one or more nebulization during their visit to the physician.

Looking to identify factors associated with those infants with RW and high predictive index for asthma, we analyzed the pattern of prescription of discharge medications. Among the 121 infants with stringent API predictive of asthma and 132 infants with stringent API not predictive of asthma, 83 (68.6\%; 95\% Cl = 59.4\%, 76.6\%) and 90 (68.2\%; $95 \% \mathrm{Cl}=59.4 \%, 76.8 \%$ ), respectively, were discharged on oral medications (OR 1.01; 95\% Cl =0.6, 1.7; $\mathrm{P}=0.5260$ ) and 55 (45.5\%; $95 \% \mathrm{Cl}=36.5 \%, 54.7 \%)$ and $33(25 \% ; 95 \% \mathrm{Cl}=$ $18.1 \%, 33.4 \%)$ had received short-acting inhaled bronchodilators $(\mathrm{OR}=2.5 ; 95 \% \mathrm{Cl}=1.5,4.3 ; \mathrm{P}=0.0006)$ for relief of wheezing, respectively. Among the 121 infants with stringent API predictive of asthma and 132 infants with stringent API not predictive of asthma, 68 (56.2\%; $95 \% \mathrm{Cl}=46.9 \%$,
Table 5 Discharge Medication of the toddlers with recurrent wheezing from their last visit to a physician for acute onset wheezing and/or cough, cold or breathing difficulty where one or more medications to relieve wheezing was prescribed.

\begin{tabular}{|c|c|c|}
\hline Medications prescribed & Nos. & $\begin{array}{l}\text { Percentage } \\
(95 \% \mathrm{Cl})\end{array}$ \\
\hline $\begin{array}{l}\text { Oral Medicine for Wheezing } \\
\text { (Salbutamol) }\end{array}$ & 173 & $\begin{array}{c}68.4 \\
(62.2,74.0)\end{array}$ \\
\hline $\begin{array}{l}\text { Inhaled Medicine for relieving } \\
\text { wheezing (Salbutamol) }\end{array}$ & 70 & $\begin{array}{c}27.7 \\
(22.3 .0,33.7)\end{array}$ \\
\hline $\begin{array}{l}\text { Inhaled Medicine for preventing } \\
\text { wheezing (Inhaled Corticosteroids) }\end{array}$ & 67 & $\begin{array}{c}26.5 \\
(21.2,32.4)\end{array}$ \\
\hline Oral Prednisolone & 132 & $\begin{array}{c}52.2 \\
(45.8,58.4)\end{array}$ \\
\hline $\begin{array}{l}\text { Oral Chlorpheniramine in any } \\
\text { of the forms }\end{array}$ & 81 & $\begin{array}{c}32.0 \\
(26.4,38.2)\end{array}$ \\
\hline $\begin{array}{l}\text { Oral third generation antihistamines } \\
\text { (Cetirizine, Loratidine) }\end{array}$ & 14 & $\begin{array}{c}5.5 \\
(3.2,9.3)\end{array}$ \\
\hline Oral Bromhexine & 19 & $\begin{array}{c}7.5 \\
(4.7,11.7)\end{array}$ \\
\hline Oral Antibiotics (any one of them) & 53 & $\begin{array}{c}20.9 \\
(16.2,26.6)\end{array}$ \\
\hline
\end{tabular}

$65.1 \%)$ and 64 (48.5\%; 95\% Cl = 39.8\%, 57.3\%), respectively, were discharged on oral steroids (OR 1.36; $95 \% \mathrm{Cl}=0.83$, 2.23; $\mathrm{P}=0.2191)$ and 51 (42.2\%; $95 \% \mathrm{Cl}=33.3 \%, 51.5 \%)$ and $16(12.1 \% ; 95 \% \mathrm{Cl}=7.3 \%, 19.2 \%)$ had received short-acting inhaled steroids $(\mathrm{OR}=5.28 ; 95 \% \mathrm{Cl}=2.8,9.97 ; \mathrm{P}<0.0001)$ for relief of wheezing, respectively. Prescriptions for both the antibiotics and the antihistamines were statistically not significant.

\section{Discussion}

In this first longitudinal follow-up study (Barbados Asthma, Atopic Dermatitis and Allergic Rhino-conjunctivitis Study) of a birth cohort, we report on the prevalence of RW at 18 months of age and the factors predictive of asthma in late childhood. The baseline demography (Table 1) of the studied cohort was representative of the babies born in Barbados over the same period. The findings from this study show that $31.1 \%$ of the toddlers had RW by the age 
of 18 months and the same number of children had RW during their first year of life. This is much higher than those reported from many European countries and even higher than those reported from neighboring Latin American countries. ${ }^{20-23}$ International comparisons of the prevalence of RW during the first few years of life have found a high prevalence of this condition, with large variability in different regions of the world. ${ }^{19-22}$ Prevalences of RW in infancy in the Latin America and Caribbean (LAC) region have been reported to be higher as compared to those of the European region. ${ }^{21-23}$ It is also reported that RW in infancy and early childhood are likely to be more severe and frequent in countries of the LAC region. ${ }^{21-24}$ Seasonal trans-Atlantic Sub-Saharan dust storms and the climatic conditions of the Caribbean region have been implicated in the high incidence of wheezing and asthma in this part of the world. ${ }^{25-27}$ The use of the multiple correlates of wheezing (having had oral bronchodilators or inhaled bronchodilators or nebulization) as opposed to the use of wheezing in most other studies, could have increased the chances of detecting asthma phenotypes in this study. A very small proportion of toddlers having been given a diagnosis of asthma in this study is in keeping with the known and inherent difficulty in making this diagnosis in young children.

Our study also looked at the prevalence of factors used for predicting asthma in preschool children. The stringent API has been statistically validated as a clinical tool for asthma predication. ${ }^{10,12-15}$ In this cohort, toddlers with RW had a significantly higher proportion of history of physician-diagnosed $A D, A R C$, and parental asthma when compared to those without RW (Table 3). All these three features are criteria for asthma prediction and their positive association with the likelihood of asthma in later childhood and into adulthood is well established. ${ }^{10,12-15}$ Nearly half of those with RW had one or both major criteria and/ or had at least two of the minor criteria of the stringent API. These findings are in keeping with the high prevalence of asthma and the high proportion of pediatric admissions from asthma among the older children seen in this population and other countries Caribbean region. ${ }^{16,17,28,29}$ Those infants with RW who had a high stringent API were more likely to have been prescribed inhaled short-acting beta-agonist and inhaled corticosteroids compared to those who did not have a high API. Another notable finding was that over half of the infants with RW did not have the factors for the stringent API. These infants are likely to have wheezed from respiratory infections and are unlikely to continue to wheeze as older children or adults. Similar observations have been made in other studies.6,7,15,24,30-32

Although a minor criterion for API, physician-diagnosed ARC (40.7\%) and symptoms suggestive of ARC (60.9\%) were the most common associated allergic conditions in infants with RW. The prevalence rate of ARC which was physician-diagnosed, was based on symptoms and signs along with blood eosinophilia and by excluding infectious causes. The prevalence of ARC that was based on historical features may have been an over-estimation. The fact that $A D$ and $A R C$ were also seen commonly among the infants without RW suggests that these allergic conditions are very common in this population. Once again sub-Saharan dust and other environmental allergens have been implicated in the causation and trigger of ARC in children and adults. ${ }^{33,34}$
The majority (nearly 60\%) of the toddlers with RW utilize the publicly funded polyclinics and the Accident and Emergency facility at the QEH. In these settings, these children are managed by General Practitioners or Emergency Medicine physicians with very little input from pediatricians, if at all. Only one-fifth of these toddlers with RW receive the care for their acute wheezing symptoms by a pediatrician in their private office. The proportion of parents of toddlers with RW using the publicly funded services, which are free at the point of delivery, is higher than the overall distribution of service utilization among the public and private care providers for the primary care of children in this country. ${ }^{35}$ This may be reflective of the recurrent nature of the illness and therefore the potentially high costs involved in multiple visits to the private doctors' offices that the parents would incur if they were to access private health care unless they had insurance coverage, which is not common. Another significant finding from this study was that a high percentage of these toddlers were treated with antihistamines, especially first-generation antihistamines particularly Chlorpheniramine, Bromhexine, an expectorant and antibiotics.

Undertreatment as well as overtreatment of asthma with all these treatments are not uncommon and not only unnecessary but can be harmful or even dangerous in young children with symptoms of asthma phenotypes. ${ }^{15,36}$ A high proportion of all the pediatric medical admissions in this country are for wheezing in children from asthma including those of preschool children with RW. ${ }^{17,28}$ Sub-optimal management of severe wheezing in preschool children with RW may be partly responsible for the high proportion of pediatric admissions for wheezing in this country. This is evident from the fact that a significant number of infants and toddlers with RW and a high asthma predictive index continued to be discharged home on oral bronchodilators and even a higher proportion of these infants and toddlers did not receive any inhaled steroids. Several studies from around the world have reported that a better understanding of the local epidemiology of wheezing in young children is associated with better management of these children. ${ }^{20,21,23,30,36}$

A major limitation of this study was the reliance on mothers for medical information from visits to physicians for their baby's medical care. It is not unusual for mothers to not register all of the information conveyed to them during the consultation process. Additionally, wheezing is not easily recognized in infants and toddlers. These factors may have resulted in an under-estimation of the true frequency of wheezing in these toddlers. Although studies have confirmed that regardless of previous experience with wheezing episodes, parents can reliably ascertain when their infants are currently wheezing and in conjunction with a simple and convenient questionnaire confirmed by physical examination produce an accurate tool to assess the prevalence of asthma symptoms in infants. ${ }^{18,19}$

Given the high prevalence of RW in this population, risk stratification using prediction indices may be useful for clinical and research purposes. For example, risk stratification supports the tailoring of treatment strategies such that benefits and harms may be properly weighed. It may therefore improve the follow-up of children at risk by decreasing the disease burden and improving management, 
resulting in fewer respiratory symptoms, exacerbations, and emergency medical visits, as has been shown in previous studies. ${ }^{22,37,38}$

In conclusion, nearly a third of toddlers by the age of 18 months and infants in this population have RW which is a common denominator in different asthma phenotypes in children. Nearly half of the infants with RW had at least one or more major criteria and/or at least two of the minor criteria of the stringent API and are likely to continue to wheeze into their school-age and possibly into adulthood. Findings from this study point to the fact that the high prevalence of asthma phenotype among toddlers presents a significant care and management challenge, given the potential severity of these conditions in this population. Additionally, the continuing care of nearly half of these children who are likely to continue to wheeze as older children and adults would be a significant burden to public health in this population.

\section{Acknowledgments}

The authors are thankful to all those mothers who have taken their time and have been so cooperative to maintain the necessary records as well as sharing the necessary information with them during the investigations and taking so much interest in the well-being of their children. They are also thankful to Dr. Janine Taitt and Mrs. Richa Kumar for proof-reading the manuscript at the preparation stages.

\section{Conflicts of interest}

The authors have no conflict of interest to declare.

\section{References}

1. Carlsen KCL, Pijnenburg M. Identification of asthma phenotypes in children. Breath. 2011;8:38-44. https://doi. org/10.1183/20734735.004611

2. Reddy MB, Covar RA. Asthma phenotypes in childhood. Curr Opin Allergy Clin Immunol. 2016;16(2):127-134. https://doi. org $/ 10.1097 / \mathrm{ACl} .0000000000000252$

3. Bousquet J, Anto J, Auffray C, Akdis M, Cambon-Thomsen A, Keil T, et al. MeDALL (Mechanisms of the Development of ALLergy): an integrated approach from phenotypes to systems medicine. Allergy. 2011;66:596-604. https://doi. org/10.1111/j.1398-9995.2010.02534.x

4. Spycher BD, Silverman M, Pescatore AM, Beardsmore CS, Kuehni CE. Comparison of phenotypes of childhood wheeze and cough in 2 independent cohorts. J Allergy Clin Immunol. 2013 Nov;132(5):1058-1067. https://doi.org/10.1016/j.jaci.2013.08.002

5. Lötvall J, Akdis CA, Bacharier LB, Bjermer L, Casale TB, Custovic A, et al. Asthma endotypes: a new approach to classification of disease entities within the asthma syndrome. J Allergy Clin Immunol. 2011;127:355-360. https://doi. org/10.1016/j.jaci.2010.11.037

6. Taussig LM, Wright AL, Holberg CJ, Halonen M, Morgan WJ, Martinez FD. Tucson Children's Respiratory Study: 1980 to present. J Allergy Clin Immunol. 2003;111(4):661-675. https:// doi.org/10.1067/mai.2003.162

7. Sears MR, Greene JM, Willan AR, Wiecek EM, Taylor DR, Flannery EM, et al. A longitudinal, population-based, cohort study of childhood asthma followed to adulthood. N Engl J Med. 2003;349(15):1414-1422. https://doi.org/10.1056/ NEJMoa022363

8. Savenije OE, Granell R, Caudri D, Koppelman GH, Smit HA, Wijga A, et al. Comparison of childhood wheezing phenotypes in 2 birth cohorts: ALSPAC and PIAMA. J Allergy Clin Immunol. 2011;127:1505-1512. https://doi.org/10.1016/j.jaci.2011.02.002

9. Custovic A, Soderstrom L, Ahlstedt S, Sly PD, Simpson A, Holt PG. Allergen-specific IgG antibody levels modify the relationship between allergen-specific lgE and wheezing in childhood. J Allergy Clin Immunol. 2011;127:1480-1485. https://doi. org/10.1016/j.jaci.2011.03.014

10. Castro-Rodriguez JA. The Asthma Predictive Index: early diagnosis of asthma. Curr Opin Allergy Clin Immunol. 2011;11:157161. https://doi.org/10.1097/ACl.0b013e3283464c4a

11. Martinez FD. What have we learned from the Tucson Children's Respiratory Study? Paediatr Respir Rev. 2002;3: 193-197. https://doi.org/10.1016/S1526-0542(02)00188-4

12. Rodriguez-Martinez CE, Sossa-Briceno MP, CastroRodriguez JA. Discriminative properties of two predictive indices for asthma diagnosis in a sample of preschoolers with recurrent wheezing. Pediatr Pulmonol. 2011;46:1175-1181. https://doi.org/10.1002/ppul.21493

13. Leonardi NA, Spycher BD, Strippoli MP, Frey U, Silverman M, Kuehni CE. Validation of the Asthma Predictive Index and comparison with simpler clinical prediction rules. J Allergy Clin Immunol. 2011;127:1466-1472. https://doi.org/10.1016/j. jaci.2011.03.001

14. Fouzas S, Brand PL. Predicting persistence of asthma in preschool wheezers: crystal balls or muddy waters? Paediatr Respir Rev. 2013;14:46-52. https://doi.org/10.1016/j.prrv. 2012.08.004

15. Caudri D, Wijga AH, Smit HA, Koppelman GH, Kerkhof $M$, Hoekstra MO,et al. Asthma symptoms and medication in the PIAMA birth cohort: evidence for under and overtreatment. Pediatr Allergy Immunol. 2011;22:652-659. https://doi. org/10.1111/j.1399-3038.2011.01193.x

16. Howitt ME, Roach TC, Naidu R. Prevalence of asthma and wheezing illnesses in Barbadian school children: the Barbados National Asthma \& Allergy Study [Abstract]. West Indian Med J. 1998;47 (Suppl 2):22-23.

17. Kumar A, Cherian J. Trends in hospitalization and mortality pattern among children in Barbados, 1987-98. West Indian Med J. 2000;49 (suppl.):XX.

18. Mallol J, García-Marcos L, Aguirre V, Martinez-Torres A, Perez-Fernández V, Gallardo A, et al. The International Study of Wheezing in Infants: questionnaire validation. Int Arch Allergy Immunol. 2007;144(1):44-50. https://doi. org $/ 10.1159 / 000102613$

19. Chong Neto HJ, Rosario N, Dela Bianca AC, Solé D, Mallol J. Validation of a questionnaire for epidemiologic studies of wheezing in infants. Pediatr Allergy Immunol. 2007 Feb;18(1):8687. https://doi.org/10.1111/j.1399-3038.2006.00488.x

20. Huffaker MF, Phipatanakul W. Utility of the Asthma Predictive Index in predicting childhood asthma and identifying disease-modifying interventions. Ann Allergy Asthma Immunol. 2014;112(3):188-190. https://doi.org/10.1016/j.anai.2013.12.001

21. Asher MI, Montefort S, Björkstén B, Lai CK, Strachan DP, Weiland SK, et al. Worldwide time trends in the prevalence of symptoms of asthma, allergic rhinoconjunctivitis, and eczema in childhood: ISAAC Phases One and Three repeat multicountry cross-sectional surveys. Lancet. 2006;368:733-743. https:// doi.org/10.1016/S0140-6736(06)69283-0

22. Mallol J, García-Marcos L, Solé D, Brand P, EISL Study Group. International prevalence of recurrent wheezing during the first year of life: variability, treatment patterns and use of health resources. Thorax. 2010;65:1004-1009. https://doi. org/10.1136/thx.2009.115188 
23. Assis EV, Sousa MNA, Feitosa MNA, Souza ACC, Leitao PA Quental OB, et al. Prevalence of recurrent wheezing and its risk factors. Rev. bras. development growth. Hmm. [online]. 2014;24(1):80-85 [cited 2020-07-10].

24. Chong-Neto HJ, Silva Ferreira WF, Urrutia-Pereira M, Solé D, Rosário NA. Recurrent wheezing in infancy: Is the tropic different? Ann Allergy Asthma Immunol. 2020;125(1):115. https:// doi.org/10.1016/j.anai.2020.02.015

25. Guilbert TW. Identifying and managing the infant and toddler at risk for asthma. J Allergy Clin Immunol. 2010;126(2):417422. https://doi.org/10.1016/j.jaci.2010.06.024

26. Akpinar-Elci M, Martin FE, Behr JG, Diaz R. Saharan dust, climate variability, and asthma in Grenada, the Caribbean. Int J Biometeorol. 2015;59(11):1667-1671. https://doi.org/10.1007/ s00484-015-0973-2

27. Cadelis G, Tourres R, Molinie J. Short-term effects of the particulate pollutants contained in Saharan dust on the visits of children to the emergency department due to asthmatic conditions in Guadeloupe (French Archipelago of the Caribbean). PLoS One. 2014;9(3):e91136. https://doi.org/10.1371/journal. pone.0091136

28. Gyan K, Henry W, Lacaille S, Laloo A, LamseeEbanks C, McKay S, et al. African dust clouds are associated with increased paediatric asthma accident and emergency admissions on the Caribbean island of Trinidad. Int J Biometeorol. 2005;49(6):371-376. https://doi.org/10.1007/ s00484-005-0257-3

29. Kumar A, Krishnamurthy K, Belgrave N. Burden of hospitalizations and mortality from acute severe asthma among children in Barbados, 2013-2016. 64th Annual CARPHA Health Research Conference, Port of Spain, 20-22 June, 2019.

30. Thongkham D, Tran J, Clunes MT, Brahim F. Prevalence and severity of asthmatic symptoms in Grenadian school children: the Grenada National Asthma Survey. BMJ Open. 2015 Oct 19;5(10):e008557. https://doi.org/10.1136/ bmjopen-2015-008557
31. Bessa OA, Leite ÁJ, Solé D, Mallol J. Prevalence and risk factors associated with wheezing in the first year of life. J Pediatr (Rio J). 2014;90(2):190-196. https://doi.org/10.1016/j. jped.2013.08.007

32. Kuehni CE, Strippoli MP, Low N, Brooke AM, Silverman M. Wheeze and asthma prevalence and related health-service use in white and South Asian pre-schoolchildren in the United Kingdom. Clin Exp Allergy. 2007;37:1738e46. https://doi. org/10.1111/j.1365-2222.2007.02784.x

33. Guilbert TW, Mauger DT, Lemanske RF. Childhood asthmapredictive phenotype. J Allergy Clin Immunol Pract. 2014;2: 664-670. https://doi.org/10.1016/j.jaip.2014.09.010

34. Meltzer EO, Blaiss MS, Naclerio RM, Stoloff SW, Derebery MJ, Nelson HS, et al. Burden of allergic rhinitis: allergies in America, Latin America, and Asia-Pacific adult surveys. Allergy Asthma Proc. 2012;33:S113-S141. https://doi. org/10.2500/aap.2012.33.3603

35. Biagini JM, LeMasters GK, Ryan PH, Levin L, Reponen T, Bernstein $\mathrm{Tl}$, et al. Environmental risk factors of rhinitis in early infancy. Pediatr Allergy Immunol. 2006;17(4):278-284. https://doi.org/10.1111/j.1399-3038.2006.00386.x

36. Kumar A, Singh K, Krishnamurthy K, Nielsen LA. Exploring the role of the public and private funded primary health care facilities for children in a pluralistic health care setting of Barbados - one of the English Caribbean countries. Int J Prev Med. 2015;6(11):116-120. doi: 10.4103/2008-7802.169073

37. Heilborn H, Pegelow K-O, Odeblad E. Effect of bromhexine and guaiphenesine on clinical state, ventilatory capacity and sputum viscosity in chronic asthma. Scand J Respir Dis. 1976;57(2):88-96.

38. Beigelman A, Bacharier LB. Management of preschool recurrent wheezing and asthma: a phenotype-based approach. Curr Opin Allergy Clin Immunol. 2017;17(2):131-138. https:// doi.org/10.1097/ACl.0000000000000344 